\title{
Correction to: Rationale and design of the Caloric Restriction and Exercise protection from Anthracycline Toxic Effects (CREATE) study: a 3-arm parallel group phase II randomized controlled trial in early breast cancer
}

Amy A. Kirkham", D. Ian Paterson², Carla M. Prado ${ }^{3}$, John R. Mackey ${ }^{4}$, Kerry S. Courneya ${ }^{5}$, Edith Pituskin ${ }^{6}$ and Richard B. Thompson ${ }^{1}$

\section{Correction to: BMC Cancer}

https://doi.org/10.1186/s12885-018-4778-7

Following publication of the original article [1], we have been notified that one of the author names was listed incorrectly. Both incorrect and correct author names are presented below.

- Originally published name: John M Mackey

- Correct name: John R Mackey

Author details

'Department of Biomedical Engineering, University of Alberta, 1098 ResearchTransition Facility, 8308-114 Street, Edmonton, AB T6G 2V2, Canada. ${ }^{2}$ Department of Medicine, Division of Cardiology, University of Alberta, Edmonton, Canada. ${ }^{3}$ Department of Agricultural, Food \& Nutrition Science, University of Alberta, Edmonton, Canada. ${ }^{4}$ Department of Oncology, University of Alberta, Edmonton, Canada. ${ }^{5}$ Faculty of Kinesiology, Sport, and Recreation, University of Alberta, Edmonton, Canada. ${ }^{6}$ Faculty of Nursing, University of Alberta, Edmonton, Canada.

Received: 9 January 2019 Accepted: 9 January 2019

Published online: 15 January 2019

\section{Reference}

1. Kirkham, et al. Rationale and design of the Caloric Restriction and Exercise protection from Anthracycline Toxic Effects (CREATE) study: a 3-arm parallel group phase II randomized controlled trial in early breast cancer. BMC Cancer. 2018;18:864. https://doi.org/10.1186/s12885-018-4778-7.

\footnotetext{
* Correspondence: amy.kirkham@ualberta.ca

1 Department of Biomedical Engineering, University of Alberta, 1098

ResearchTransition Facility, 8308-114 Street, Edmonton, AB T6G 2V2, Canada

Full list of author information is available at the end of the article
}

(c) The Author(s). 2019 Open Access This article is distributed under the terms of the Creative Commons Attribution 4.0 International License (http://creativecommons.org/licenses/by/4.0/), which permits unrestricted use, distribution, and reproduction in any medium, provided you give appropriate credit to the original author(s) and the source, provide a link to the Creative Commons license, and indicate if changes were made. The Creative Commons Public Domain Dedication waiver (http://creativecommons.org/publicdomain/zero/1.0/) applies to the data made available in this article, unless otherwise stated. 